\title{
Direitos Humanos e o Reconhecimento das Famílias Gays e Lésbicas no Brasil: os direitos fundamentais e o julgamento histórico do Supremo Tribunal Federal de 2011
}

\begin{abstract}
Resumo
Neste artigo abordo como a efetivação dos Direitos Humanos se dá a partir da aplicabilidade dos princípios constitucionais no Brasil, ao analisar alguns aspectos da decisão, considerada histórica, na luta por reconhecimento de direitos LGBT. Por meio do estudo da decisão proferida pelo Supremo Tribunal Federal em maio de 2011, este artigo analisa o reconhecimento da conjugalidade de pessoas do mesmo sexo como entidade familiar.
\end{abstract}

Palavras-chave: Direitos Humanos, Famílias gays e lésbicas, História das Famílias no Brasil, Direitos sexuais.

\author{
Claudia Regina Nichnig \\ Doutora em Ciências Humanas pela \\ Universidade Federal de Santa Catarina (UFSC). \\ Professora visitante do Programa de Pós- \\ Graduação em História da Universidade Federal \\ da Grande Dourados (UFGD). \\ Dourados, MS - Brasil \\ claudianichnig@gmail.com \\ orcid.org/0000-0002-9689-8112
}

\footnotetext{
Para citar este artigo:

NICHNIG, Claudia Regina. Direitos Humanos e o Reconhecimento das Famílias Gays e Lésbicas no Brasil: os direitos fundamentais e o julgamento histórico do Supremo Tribunal Federal de 2011. Tempo e Argumento, Florianópolis, v. 11, n. 27, p. 1585 - 191, maio/ago. 2019 .
} 


\title{
Variations on a theme without Human \\ Rights in Brazil and recognized gay and \\ lesbian families: fundamental rights and \\ historical judgment at the Supreme \\ Federal Court in May 2011
}

\begin{abstract}
In this article I discuss how the implementation of Human Rights is based on the applicability of constitutional principles in Brazil, when analyzing some aspects of the decision, considered historical, in the struggle for recognition of LGBT rights in Brazil. Through the study of the process judged at the Supreme Federal Court in May 2011, this article it also aims to analyze the trial that recognized same-sex conjugality, under the light of Human Rights.
\end{abstract}

Keywords: Human Rights. Gay and Lesbian Families. History of Families in Brazil Sexual Rights.

[...] que a conquista de direitos é tão difícil quanto curiosa. A luta pelos direitos é árdua para a geração que cuida de batalhar pela sua aquisição. E parece uma obviedade, quase uma banalidade, para as gerações que os vivem como realidades conquistadas e consolidadas (BRASIL, 2011, p. 1253).

Neste artigo, analiso como a efetivação dos Direitos Humanos se dá a partir da aplicabilidade dos princípios constitucionais no Brasil, ao abordar alguns aspectos da decisão, considerada histórica, na luta por reconhecimento de direitos LGBT no Brasil. A decisão foi proferida pelo Supremo Tribunal Federal (STF) em maio de 2011 e, a partir da análise dos votos dos/as ministros/as, trago ao debate como os Direitos Humanos são aplicados, ao consideramos que os princípios constitucionais se traduzem na efetividade dos Direitos Humanos no Brasil, o que se dá por meio da positivação da legislação constitucional. Ao tratar algumas questões referentes aos conceitos de família, sexualidade e gênero, os ministros e ministras se pronunciam a respeito dos princípios constitucionais que dão efetividade aos Direitos Humanos. 
Ao trazer o debate da conquista e reivindicação por direitos iguais inseridos nos estudos feministas e de gênero, mesmo que tenhamos tido uma chamada primeira onda do feminismo no início do século XX em torno de políticas liberais de luta das mulheres pela igualdade de direitos políticos e civis, a reivindicação por igualdade de direitos atravessa diferentes contextos históricos e é uma constante nas agendas dos movimentos feministas e LGBT. Mesmo que incluídas em uma perspectiva liberal de conquista de direitos iguais, também são lutas identitárias que reivindicam políticas e direitos para um grupo de sujeitos e, fazendo uso das palavras de Stuart Hall (2000), esses direitos "não podem ser sequer pensados" sem que atravessemos as políticas de identidade (HALL, 2000). Ou seja, se por um lado buscam um direito específico ou uma igualdade de direitos entre homens e mulheres, heterossexuais e homossexuais, por outro lado se traduzem em lutas que constituem identidades. No caso em discussão, não somente identidades gays e lésbicas, mas de famílias gays e lésbicas.

Ao contar uma história do tempo presente, "na qual o historiador investiga um tempo que é o seu próprio tempo com testemunhas vivas e com uma memória que pode ser a sua" (AREND e MACEDO, 2012, p. 6), a proposta do artigo é articular História e o Direito para pensar as reivindicações das pessoas LGBT como direitos humanos. Ao incluir esse debate é possível observar, a partir de uma perspectiva de gênero, a ampliação dos direitos das mulheres e das pessoas LGBT durante todo o século XX, trazendo como foco o reconhecimento da conjugalidade vivida por esses casais como uma das possibilidades de se constituir como família. A proposta é pensar como os Direitos Humanos positivados no Brasil a partir dos princípios constitucionais, puderam garantir o direito ao exercício da conjugalidade por casais do mesmo sexo, utilizando as lentes dos estudos de gênero e feministas, dando visibilidade às reivindicações de sujeitos invisibilizados e marginalizados pela história.

Em 2018 foram comemorados 70 anos da Declaração Universal dos Direitos Humanos (DUDH). Mesmo que envolto em controvérsias, o Estado Brasileiro e suas diferentes instâncias fizeram um esforço para promover e proteger esses direitos, principalmente ao inseri-los na Constituição Federal de 1988 por meio da positivação dos princípios constitucionais. Esses dois importantes acontecimentos históricos que marcam 
a história contemporânea mundial e do Brasil podem ser pensados a partir do que propõe a História do Tempo Presente, pois se há uma crítica em relação ao não distanciamento necessário para a análise, devido ao fato de "não poder mensurar os efeitos dos acontecimentos" (DOSSE, 2012). Ainda assim, ambos colocam em xeque a possibilidade de reconhecimento de direitos iguais para as mulheres e para a população LGBT, transformando realidades e pautando agendas e políticas públicas.

Como os direitos humanos são regras internacionais e, conforme o artigo primeiro da declaração, "Todos os seres humanos nascem livres e iguais em dignidade e direitos" (UNICEF, 2019)., suas diretrizes precisam ser positivadas pelos países que a adotam. Além disso, conforme a Assembleia Geral da Organização das Nações Unidas (ONU), de 10 de dezembro de 1948, os países que se tornaram membros fundadores da organização firmavam a declaração internacional (UNRIC, 2018). ${ }^{1}$

Chamada de constituição cidadã, em sua promulgação em 1988, a Constituição Federal previu princípios reconhecidos como a positivação ou possibilidade da aplicabilidade dos direitos humanos no ordenamento jurídico brasileiro. Mesmo que desde o princípio a Constituição tenha recebido críticas, principalmente dos movimentos sociais que reivindicavam direitos das populações invisibilizadas na sociedade como mulheres, indígenas, crianças, entre outras, após 30 anos da promulgação é possível considerar que os princípios são tidos como ganhos efetivos da carta magna de 1988, mas também se traduzem desafios constantes em relação a sua aplicabilidade.

A Constituição da República Federativa do Brasil destaca, no artigo $1^{\circ}$, que seus fundamentos são a soberania, a cidadania, a dignidade da pessoa humana, os valores sociais do trabalho e da livre iniciativa e o pluralismo político, os quais são princípios fundamentais de direitos humanos. Os princípios constitucionais como os da igualdade, da dignidade da pessoa humana, da não discriminação e da liberdade serão aqui discutidos a partir do julgamento do STF-, ${ }^{2}$ como uma forma de efetivação dos direitos humanos.

\footnotetext{
${ }^{1}$ Disponível em : https://www.unric.org/pt/actualidade/32369-2018-comemora-os-70-anos-da-declaracaouniversal-dos-direitos-humanos. Acesso em 01.12.2018.

2 Disponível em: www.planalto.gov.br. Acesso em 11.02.2019.
} 
O STF e o reconhecimento da conjugalidade gay e lésbica como união estável

O STF é considerado a última instância do poder judiciário brasileiro, responsável por decidir processos que tratem de infração à Constituição Federal. Tem como competência a "guarda da Constituição" e lhe cabe "processar e julgar originariamente a ação direta de inconstitucionalidade de lei ou ato normativo federal ou estadual", conforme dispõe o artigo 102, inciso I, alínea " $a$ " da Constituição. A decisão que reconheceu a união estável entre pessoas do mesmo sexo e que analiso neste artigo resulta de dois processos que tramitaram no STF. A Ação Direta de Inconstitucionalidade (ADI) n. 4277, ajuizada pela Procuradoria Geral da República, e o pedido de Arguição de Descumprimento de Preceito Fundamental (ADPF) n. 132, ajuizada pelo representante do Estado do Rio de Janeiro, então governador Sérgio Cabral, ${ }^{3}$ ajuizada em face da Assembleia Legislativa do Estado do Rio de Janeiro e o Tribunal de Justiça do mesmo Estado.

A ADPF foi ajuizada visando reconhecer como uniões estáveis as chamadas uniões homoafetivas, buscando a interpretação conforme a Constituição e aos artigos 19, II e V1, e 33, ambos do Decreto-lei estadual n. 220/752. O objetivo da ação foi assegurar aos servidores públicos estaduais do Rio de Janeiro que vivem em conjugalidade com pessoas do mesmo sexo, os benefícios previstos no Decreto-lei estadual n²20/752. Já a ADI tinha como finalidade conferir "interpretação conforme a Constituição" em relação ao artigo 1.723 do Código Civil. Ao final, o processo que inicialmente foi ajuizado como ADPFn. 132, foi conhecido como ADI, sendo ambas, ADPF n. 132 e ADI n. 4277, julgadas em conjunto, ou seja, foi dada uma só decisão aos dois processos.

A decisão final foi no sentido de considerar que a união contínua, pública e duradoura entre duas pessoas do mesmo sexo seja considerada união estável, como entidade familiar, conforme determina a Constituição em seu artigo 226 e no Código Civil Brasileiro em seu artigo 1273. É importante lembrar que não foi permitido o casamento, mas especialmente o reconhecimento da união estável. Em relação ao casamento, uma resolução posterior do Conselho Nacional de Justiça determinou que os cartórios o registrassem, mas foi uma decisão posterior à tomada em 2011.

\footnotetext{
3 Sérgio Cabral foi governador do Estado do Rio de Janeiro com mandato de 2007 a 2010, reeleito em outubro de 2010 para o mandato de 2011 a 2014, pelo Partido do Movimento Democrático Brasileiro (PMDB).
} 
Sobre a possibilidade de configurar uma relação entre duas pessoas como união estável, a Constituição reconheceu como entidade familiar a conjugalidade formada por duas pessoas de sexos diferentes, reconhecida como a união pública, duradoura e como ânimo de constituir família. Até 1988 os casais que não registraram contrato civil de casamento não eram considerados como família e unir-se fora do casamento era a forma mais comuns de relacionamento entre as pessoas, mesmo que fora do crivo do estado. Os casais unidos, mesmo fora do casamento civil e antes do reconhecimento da união estável, se reconheciam como família pois esses modos informais são uma prática no Brasil, o que eu chamei de famílias marcadas por "improvisações" (NICHNIG, 2013). Essas famílias informais se traduzem como uma nova modalidade de arranjo familiar, como propõe Claudia Fonseca (2008), e por serem já reconhecidas socialmente no Brasil é que posteriormente o texto constitucional formalizou a modalidade, afirmando que tanto essas uniões informais podem ser reconhecidas com ou sem um documento formal, mas também que a lei deve "facilitar a conversão da união estável em casamento". Assim, no contexto brasileiro marcado pela não formalização das relações conjugais, enquanto o casamento civil foi sendo contrato imposto pelo estado, há uma resistência dos sujeitos a essa imposição formal e estatal, seja por questões econômicas ou de ordem subjetiva, não querem e não pretendem a interferência do Estado e a formalização através de um contrato civil de casamento.

Desta forma, se a previsão de possibilidade jurídica da união estável é bastante recente (somente com a constituição de 1988), ela não incluiu a possibilidade do reconhecimento para as famílias gays e lésbicas, pois estava restrita ao casal formado por um homem e uma mulher. Em 2002, o novo Código Civil Brasileiro ainda tratou da possibilidade do reconhecimento do casal formado por "homem e a mulher [que] manifestam, perante o juiz, a sua vontade de estabelecer vínculo conjugal" (BRASIL, 2002). ${ }^{4}$ O vínculo conjugal, portanto, se conclui por essa união dual entre pessoas de sexos diferentes, realizada entre um homem e uma mulher.

\footnotetext{
${ }^{4}$ Artigo 1514, Lei 10.406, de 10 de janeiro de 2002. Disponível em: www.planalto.gov.br. Acesso em 17.06.2019.
} 
Por não existir previsão legal é que a decisão do Supremo Tribunal Federal que reconhece o direito de gays e lésbicas quando mantêm relações afetivo-conjugais de terem reconhecido sua união como família (na forma da união estável) traz um forte efeito simbólico, pois produz reconhecimentos e consequentemente produz direitos para os casais. Se estes casais não tinham a igualdade jurídica em relação aos casais heterossexuais, a decisão do STF vem suprir esta lacuna legislativa, mesmo que essa não positivação do direito traga incertezas jurídicas. De fato, foi um grande passo dado, mesmo que haja um grande questionamento do fato do Poder Judiciário estar exercendo atividades que são restritas ao Poder legislativo, sendo que esse fenômeno é chamado de “judicialização da política.”5

Maria Eugenia Bunchaft (2011) trata de “constitucionalismo democrático" quando o judiciário, através de aplicação de seus princípios constitucionais, potencializa "o engajamento público expresso em termos de interações entre as cortes e os movimentos sociais" (BUNCHAFT, 2011, p. 158). Diante da inoperância e da não vontade do legislativo brasileiro de votar projetos de lei que tratam de temáticas que abordam questões relativas à sexualidade e às questões de gênero, pode-se considerar o judiciário como “vanguarda da sociedade, protegendo minorias estigmatizadas pelo processo político majoritário, ainda que resolvendo questões morais controvertidas" (BUNCHAFT, 2011, p. 160).

Quando se trata de questões de moralidade, o judiciário e o legislativo são permeados por diferentes discursos, sejam eles conservadores, mas também de concessão de direitos às minorais. Em 2011, o contexto histórico não era o mesmo que se apresenta a partir 2014, no qual as discussões de gênero passam a sofrer ataques, principalmente em torno do Plano Nacional de Educação (PNE), e com ainda maior intensidade durante as eleições presidenciais de 2018 (NICHNIG, 2019). No momento da decisão analisada, o Brasil vivia o primeiro mandato da presidenta Dilma Rousseff e as

\footnotetext{
5 Muito foi questionado acerca do poder judiciário estar exercendo, nesse caso, o papel que deveria ser desempenhado pelo Poder Legislativo, o que pode ser interpretado como uma forma de "judicialização da política." (VIANNA, 1999; VIANNA, BURGOS e SALLES, 2007; MACIEL e KOERNER, 2002; NIGRO, 2012). Segundo o ministro Celso de Mello, esse protagonismo do judiciário pode ser entendido como uma “expressiva ampliação de suas funções institucionais pela própria Constituição”. ADI 4277, STF, p. 1429. A decisão também foi criticada por ser uma forma de "ativismo judicial.
} 
discussões sobre gênero, sexualidade, homossexualidade não tinha ainda recebido o tom acusatório de "ideologia de gênero" que posteriormente fez com que muitas pessoas se colocassem contrariamente aos debates de gênero no âmbito público, seja na concessão de direitos, políticas públicas e no ensino das temáticas relativas a gênero e direitos humanos nas escolas.

Diante da inoperância das esferas legislativas, permeadas por interesses de cunho pessoal, ideológico ou religioso, o sistema jurídico pode ser um terreno fértil para o reconhecimento de direitos a partir das discussões relativas aos movimentos feministas e homossexuais. São agendas políticas que visam à positivação dos direitos através de legislações, considerando-os como "política de reconhecimento" (FRASER, 2008) que, por outro lado, também se revestem em lutas identitárias, ao buscar o reconhecimento como sujeitos. Vale lembrar que esse reconhecimento não é só dos próprios sujeitos, mas também das famílias formadas por casais do mesmo sexo, marcadas pela aceitação pelos familiares, nos locais de trabalho, permeados por aproximações e distanciamentos.

$\mathrm{Na}$ análise que faço da decisão, concentrei-me nos votos dos ministros e ministras e não nos argumentos das partes, pois não se tratou de uma ação movida por um casal ou pessoa, mas sim por entidades representando grupos de pessoas. Assim, na ADI em que o objetivo era reconhecer o direito dos casais que viviam em conjugalidade como entidade familiar a partir da possibilidade do registro ou reconhecimento da união estável, analisei as principais partes do processo, como os votos e o acórdão final. É importante registrar a participação de representantes da entidade civil que atuaram no processo, os chamados amicus curiae, pois traduzem uma forma de se fazer ouvir os grupos e entidades, favoráveis e contrários aos direitos da população LGBT e das famílias de mesmo sexo. Suas intervenções permitiram amparar a posição tomada por cada um/um dos/as ministros/as (NICHNIG, 2018).

Além de partes dos processos, como os votos e a decisão final, o acórdão foi analisado na íntegra. Busquei, também, assistir aos julgamentos e à sustentação oral realizada por participantes da sociedade civil que aturam como amicus curiae, que estão disponíveis no YouTube e no site do STF. Dessa forma, ao analisar os processos, fui inspirada pelos trabalhos de Cristina Scheibe Wolff (1999) e Marlene de Fáveri (2010), 
historiadoras que utilizam processos judiciais como fonte de pesquisa para estudar as mulheres, as famílias e as relações de gênero no Brasil. Minha percepção é que no acórdão e principalmente durante o julgamento (que entendo como um espaço ritual), é possível perceber a atuação dos operadores do direito como em um jogo, um teatro, onde cada jogador/ator desempenha seu papel no julgamento (SCHRITZMEYER, 2012).

Nesses processos judiciais se entrecruzam inúmeras vozes das partes, entidades que propõem o processo, através de seus/suas advogados/as, as provas apresentadas, bem como diversos documentos como textos, falas, pareceres, legislações de outros países, argumentos favoráveis ao reconhecimento do direito trazidos principalmente pela importante participação das entidades favoráveis aos direitos das pessoas do mesmo sexo, como a família (NICHNIG, 2018). Minha intenção foi analisar essas partes do processo como fonte de pesquisa histórica, sempre levando em conta a sua produção, pensando quem as produziu e com qual intencionalidade. Dessa forma, a produção e análise de fontes documentais a partir dos acontecimentos faz com que as práticas dos sujeitos e das famílias de gays e lésbica, ou do próprio poder judiciário produzam discursos, que são considerados históricos, como nos lembra Michel Foucault (2009):

[...] em nossos dias, a história é o que transforma documentos em monumentos e que desdobra, onde se decifravam rastros deixados pelos homens, onde se tentava reconhecer em profundidade o que tinham sido, uma massa de elementos que devem ser isolados, agrupados, tornados pertinentes, inter-relacionados, organizados em conjuntos. Havia um tempo em que a arqueologia, como disciplina dos monumentos mudos, dos rastros inertes, dos objetos sem contexto e das coisas deixadas pelo passado, se voltava para a história e só tomava sentido pelo restabelecimento de um discurso histórico; que poderíamos dizer, jogando um pouco com as palavras, que a história, em nossos dias, se volta para a arqueologia - para a descrição intrínseca do monumento (FOUCAULT, 2009, p. 8).

A partir dessa perspectiva foucaultiana analiso o discurso produzido e reforçado por pesquisadores(as)/professores(as)/juristas que consideram que as famílias de pessoas do mesmo sexo devem ser consideradas como uma forma de diversidade familiar ou como "novas famílias". Os discursos produzem práticas e, portanto, o fato de buscarem o reconhecimento da união estável ou o casamento significa que esses sujeitos também 
foram socializados na mesma lógica familiar, em que esta instituição tem uma centralidade na sociedade. Claro que não todos os casais buscam estar inseridos nessa lógica, da mesma forma que alguns casais heterossexuais optam pelo registro da união/casamento e outros não, mas quando se trata de sujeitos alijados de muitos direitos, o reconhecimento social que produz um ritual como o casamento traz muitas consequências para suas vidas como sujeitos.

\section{Sexo, gênero, sexualidade, homossexualidade e homofobia no Supremo Tribunal Federal}

O STF visa proteger as consideradas minorias," expostas a "situações de vulnerabilidades jurídica, social, econômica ou política" (BRASIL, 2011 p. 1408) e por esse motivo o poder judiciário, inserido em um estado democrático, deve assegurar o acesso aos direitos por todas as pessoas. Gustavo Lins Ribeiro (2012) observa que uma minoria, que mesmo quando majoritária numericamente "não detém a supremacia na história da conformação de uma coletividade mais abrangente. Em geral, as minorias precisam adaptar-se ou lutar por seus direitos, em face dos que definem o ambiente econômico, jurídico-legal, político e cultural mais amplo" (RIBEIRO, 2012, p. 219). Celso de Mello (2011), um dos ministros que votaram na decisão, diz que a "proteção das minorias analisada na perspectiva material de democracia constitucional", seria “defender as minorias contra eventuais excessos da maioria[...] diante da inércia do Estado" (BRASIL, 2011, p. 1404).

Vale ressaltar que diferentes dimensões da relação afetivo conjugal devem estar presentes para o reconhecimento das famílias formadas por pessoas do mesmo sexo, e como veremos nesse texto, em que não se pretendeu focar na esfera da sexualidade, mas sim no afeto presente nas relações, como uma estratégia utilizada para o reconhecimento jurídico. Assim, a conjugalidade pressupõe a "vivência das dimensões da sexualidade, do auxílio mútuo, e do envolvimento emocional” (RIOS, 2011, p. 89) e ao

\footnotetext{
${ }^{6}$ Como minorias, não me refiro a termos numéricos, mas ao processo de exclusão e discriminação social e jurídico a que são submetidas as mulheres, negros e negras, lésbicas, gays, bissexuais, travestis, transexuais, transgêneros, populações indígenas, deficientes, no Brasil, em termos de relações de poder.
} 
desfocar a atenção da sexualidade e chamar atenção para o afeto que os casais nutrem entre si, foi uma forma encontrada para o reconhecimento no âmbito jurídico.

O ministro Carlos Ayres Brito (2011) foi bastante profundo ao tecer suas considerações e fundamentar voto como relator dos processos. Além de enfocar a dimensão sexual da relação afetivo conjugal, o relator trouxe conceitos como os de gênero, sexualidade e homossexualidade, entre outros. Para Brito (2011), as diferenciações entre homens e mulheres estão "no sítio da mais natural diferenciação entre as duas tipologias do gênero humano". Ainda para o ministro, temos "duas espécies do gênero humano: a masculina e a feminina" (2011, p. 10), e estamos diante de “normas que não distinguem a 'espécie feminina' da 'espécie masculina”' (BRITO, 2011). Se não somos duas "espécies do gênero humano", pois homens e mulheres não são de “espécies" diferentes, somos todos/as seres humanos. Assim:

Diante da afirmação do ministro não é demais dizer que somos todos/as seres humanos, sendo que homens e mulheres podem se alinhar (ou não) aos comportamentos atribuídos aos gêneros masculino e feminino, "pois não existe uma determinação natural dos comportamentos de homens e mulheres" (GROSSI, 1998, p.4), como sugere o ministro. Percebo a afirmação do ministro no sentido de que somente seria permitido transitar neste binarismo, masculino e feminino, não incluindo outras possibilidades de subjetivação (NICHNIG, 2013, p. 229).

Ainda afirma o ministro que irá abordar os conceitos a partir de "uma linguagem menos antropológica e mais de lógica formal” e apresenta as diferenciações de gênero como uma "[...]dicotomia culturalmente mais elaborada que a do macho e da fêmea, embora ambas as modalidades digam respeito ao mesmo reino animal, por oposição aos reinos vegetal e mineral” (BRASIL, 2011). Para ele, algo mais "elaborado que o conceito de macho e fêmea", pois o "sexo natural" seria algo dado, que não difere diante da cultura. Assim, a explicação do ministro pode ser rechaçada a partir do que afirma Judith Butler (2003) sobre o conceito de gênero, que "não está para cultura como sexo para a natureza; ele também é meio discursivo/cultural pelo qual 'a natureza sexuada' ou 'um sexo natural' é produzido e estabelecido como 'pré-discursivo', anterior à cultura, uma superfície politicamente neutra sobre a qual age a cultura" (BUTLER, 2003, p. 25). Ambos estão mergulhados na cultura e não estão, como aponta o ministro, machos e fêmeas, 
homens e mulheres, restritos a um binarismo sem possibilidades de trânsito. Essas categorias da biologia, da natureza trazidas pelo ministro, não definem comportamentos sociais, como algo dado pela natureza, pois as desigualdades de gênero se apresentam culturalmente, pois as afirmações do ministro acabam reforçando que é a partir das diferenças biológicas entre "macho e fêmea" que se dão as diferenças no plano da cultura. Para o ministro o "sexo das pessoas, salvo expressa disposição constitucional em contrário, não se presta como fator de desigualação jurídica” (BRASIL, 2011), nesse momento o ministro ao dizer "sexo", poderia ter dito que o gênero e a sexualidade não são fatores que deveriam ser objeto de desigualdade jurídica. Vale lembrar que o que está previsto na legislação é o termo "sexo", o qual a Constituição Federal prevê especialmente ser fator impeditivo para que sejam cometidas discriminações, conforme dispõe o artigo terceiro. As conclusões do ministro relator em seu voto "além de reforçar as diferenças biológicas como implicadoras das diferenças culturais, fez muitas comparações inoportunas, impondo à natureza, as diferenças do macho e da fêmea, e consequentemente as desigualdades de gênero" (NICHNIG, 2013, p. 230). O ministro, na tentativa de debater conceitos de sexo e gênero, termina por reforçar na natureza as diferenças que se atribui ao gênero. Vale lembrar que o ministro não fez qualquer referência em seu voto que as discussões ali trazidas, "abrange um campo de estudos, o dos estudos de gênero, ou utiliza qualquer subsídio ou citação proveniente do campo, demonstrando desconhecimento sobre a temática" (NICHNIG, 2013, p. 230).

O voto do ministro relator é o que mais profundamente discute as temáticas de gênero e sexualidade através do que identificou como

[...] proibição da discriminação das pessoas em razão do sexo, seja no plano da dicotomia homem/mulher (gênero) seja no plano da orientação sexual de cada qual deles". Não se refere explicitamente à subjetividade das pessoas para optar pelo não uso puro e simples do seu aparelho genital (absenteísmo sexual ou voto de castidade), para usá-lo solitariamente (onanismo), ou, por fim, para utilizá-lo por modo emparceirado (NICHNIG, 2013, p. 231).

É importante lembrar que a primeira oportunidade em que a Constituição emprega o vocábulo "sexo" é no inciso IV do artigo terceiro. O que aponta o voto do relator é a importância da relação amorosa ou conjugal para que seja possível tratarmos 
da sexualidade das pessoas, pois o ministro entende a sexualidade como um "movediço terreno”, no qual “é impossível negar que a presença da natureza se faz particularmente forte, ostensiva" (BRASIL, 2011, p. 15). E continua explicando a respeito das diferenças biológicas entre homens e mulheres:

“[...] como essa diferente conformação anátomo-fisiológica entre o homem e a mulher se revela, usualmente, a partir dos respectivos órgãos genitais (o critério biológico tem sido esse), cada qual desses órgãos de elementar diferenciação entre partes passou a também se chamar, coloquialmente, de "sexo". O órgão a tomar o nome do ser em que anatomicamente incrustado. Mas "sexo" ou "aparelho sexual" como signo linguístico de um sistema de órgãos cumpridores das elementares funções de estimulação erótica, conjunção carnal e reprodução biológica. Três funções congênitas, como sabido, e que, por isso mesmo, precedentes de livros, escola, cultura ou até mesmo treinamento para o seu concreto desempenho. Donde sua imediata definição, não propriamente como categoria mental ou exclusiva revelação de sentimento, mas como realidade também situada nos domínios do instinto e não raro com a prevalência dele, instinto, no ponto de partida das relações afetivas. "Instinto sexual ou libido", como prosaicamente falado, a retratar o fato da indissociabilidade ou unidade incindível entre o aparelho genital da pessoa humana e essa pessoa mesma. Ficando de fora da expressão, claro, as funções meramente mecânicas de atendimento às necessidades ditas "fisiológicas" de todo indivíduo (BRASIL, 2011, p. 14).

Ainda reforçando a sexualidade como algo distante da cultura, aponta que algumas das ditas "funções" não prescindem da "cultura, dos livros ou da escola" pois a sexualidade é algo que "se define como instintivo ou da própria natureza das coisas". Para dialogar com estas afirmações lanço mão dos estudos antropológicos sobre as sexualidades os quais afirmam que "a dimensão biológica é submetida a um processo de transformação cultural que impede a definição dos limites do que é natural" (ZAMBRANO, HEILBORN, 2012, p. 414). Ou seja, não há como afirmar que a sexualidade ou, como afirma o ministro Ayres Brito (2011) "as funções congênitas" sejam realizadas independentemente da cultura dos sujeitos, pois se a sexualidade não se aprende nos "livros ou na escola", mas atravessa um longo processo de aprendizado, que perdura por toda a vida das pessoas, sendo que a cultura exerce uma papel preponderante em relação ao que é permitido e o que é proibido fazer para o exercício da sexualidade. Segundo Maria Luiza Heilborn (2006): 
Trata-se de um processo de experimentação pessoal e de impregnação, pela cultural sexual do grupo, que se acelera na adolescência e na juventude. $O$ aprendizado constitui-se na familiarização de representações, valores, papéis de gênero, rituais de interação e de práticas, presentes na noção de cultura sexual (HEILBORN, 2006, p. 35).

Quando o ministro Ayres Brito (2011) aponta que o "sexo" possui "três funções congênitas" sendo elas a "estimulação erótica, conjunção carnal e reprodução biológica”, entendo que essas dimensões não estão desconectadas das culturas em que estão inseridas, pois "as possibilidades de construção do gênero e do concerne à sexualidade, variam muito em função dos contextos culturais" (ZAMBRANO e HEILBORN, 2012, p. 414). Logo, a "estimulação erótica e a conjunção carnal” estão intrinsecamente marcadas pelas sociedades e/ou culturas. Elizabeth Zambrano e Maria Luiza Heilborn (2012) ajudam a pensar, a partir de pesquisas antropológicas, que há uma "significativa variação nas formas de vivenciar e conceituar o sexo e o gênero. As classificações por nós utilizadas devem ser relativizadas, pois há uma pluralidade de identidades na realidade social" (ZAMBRANO e HEILBORN, 2012, p. 414). Então, não há nada natural nas diferentes vivências das sexualidades, pois estas pelas marcações da cultura, mas também da orientação sexual, gênero, classe, raça, etnia, geração, deficiência etc.

A terceira dimensão da qual trata o ministro relator é a "reprodução biológica", que da mesma forma está profundamente marcada pela cultura. Além da "reprodução biológica" não se dar da mesma maneira para homens e mulheres, também há diferenciações no que se refere à reprodução para homossexuais e heterossexuais. Se a filiação biológica para os casais homossexuais estaria impedida pela natureza, com a intervenção da tecnologia seria possível o acesso à filiação biológica, além da possibilidade da filiação através do instituto da adoção. A partir da filiação, o termo homoparentalidade, trazido pelos militantes de associações francesas que buscavam designar as famílias compostas por filhos de pais e mães do mesmo sexo, se insere na luta pelo reconhecimento legal dessas famílias desde 1997.7 No Brasil, a possibilidade de adoção pelo casal do mesmo sexo não está proibida pois, para o direito, a "adoção

7 O termo criado em 1997 por militantes associativos franceses serviu, pois não existia nenhuma palavra específica, para designar as famílias compostas pelos filhos e seus pais do mesmo sexo. O objetivo era de fazer existir no espaço social e político, e ao nomeá-los, as famílias compostas por casais do mesmo sexo e seus filhos e promover o reconhecimento pela lei (COURDURIÉS, 2014, p. 31) 
conjunta, é indispensável que os adotantes sejam casados civilmente ou mantenham união estável, comprovada a estabilidade da família" (BRASIL, 2009). Apesar da nova legislação sobre adoção trazer alterações significativas, como a possibilidade de o adotado conhecer a sua origem biológica e ter acesso ao seu processo de adoção (BRASIL, 2009) não houve a permissão expressa da adoção por casais do mesmo sexo. Por outro lado, reforçando a filiação biológica, temos a possibilidade do acesso à reprodução assistida por casais gays e lésbicos, temática já bastante debatida no Brasil (GROSSI, 2003; MELLO, 2005; GROSSI, UZIEL e MELLO, 2007; TARNOVSKI, 2002; FONSECA, 2008). Anna Carolina Horstmann Amorim (2013) pesquisou as famílias lésbicas, em que mulheres são mães em um contexto de conjugalidade lésbica e a utilização de técnicas de reprodução assistida. Vale lembrar que no Brasil a Resolução n. 2.013/13, do Conselho Federal de Medicina (CFM), permitiu o acesso ao procedimento de reprodução assistida aos casais de pessoas do mesmo sexo e às pessoas solteiras. Assim, apesar de não existir uma legislação que autorize a reprodução assistida no contexto brasileiro, o próprio CFM autoriza a prática para casais de gays e lésbicos, obrigando a realização do procedimento por médicos de todo o país.

A questão da reprodução também inclui o exercício da maternidade ou paternidade, sendo que a opção por ter filhos é um dos temas afetos aos movimentos feministas, que entendem que isso é uma escolha cabível às mulheres, questionando a maternidade compulsória e a predisposição feminina para desempenhar os papéis que foram "naturalmente" a elas destinados: de mãe e esposa. A crítica da redução da sexualidade à reprodução, a partir de Monique Wittig (2007), além de discutir a imposição da reprodução, dá ênfase a vivência da sexualidade e a busca pelo prazer, aponta o desejo homossexual como uma das formas de resistência à norma (WITTIG, 2007). É importante observar que, nas relações heterossexuais, o peso da "reprodução biológica" recai mais fortemente sobre as mulheres, como as consequências de uma gravidez indesejada, a utilização ou não de métodos contraceptivos, entre outras. Em se tratando de relações afetivo conjugais entre pessoas do mesmo sexo, a questão da "reprodução biológica" também está claramente marcada pela cultura na qual está inserida. Na cultura brasileira, por exemplo, não são iguais as oportunidades de acesso às técnicas de reprodução assistida e à adoção de crianças por casais homossexuais e heterossexuais, 
apesar de não serem proibidas, seja por questões culturais seja por uma questão econômica.

O ministro relator afirma que a Constituição "opera por um intencional silêncio" (BRASIL, 2011, p. 15). em relação ao exercício da sexualidade (BRASIL, 2011, p. 15), silêncio da norma que deixa "o desempenho de tais funções sexuais ao livre arbítrio de cada pessoa". Ao não se manifestar, contudo, aceita apenas como possível a sexualidade heterocentrada. Eric Fassin (2003) interpreta esse silenciamento no contexto francês como uma recusa em politizar a sexualidade, em trazer o tema ao debate, pois "le genre et la sexualité n'auraient pas leur place dans la lumière publique, mais dans la pénombre de l'intimité" (FABRE e FASSIN, 2003, p. 25) ${ }^{8}$. O sociólogo, ao fazer uma análise do modelo norte-americano em relação ao modelo francês "on pose une alternative entre la politisation à l'américaine, et la non-politisation à la française", e conclui: "chez nous, dit-on alors, les questions sexuelles relèvent des moeurs et non de la politique, des manières privées et non du débat public, de la civilité et non de la Cité" (FABRE e FASSIN, 2003, p. 26) 9 . Se aqui se evita enfrentar o debate e paira um silêncio sobre os diversos modos de vivência das sexualidades e a consequente concessão de direitos em relação as diferentes identidades, seja ela heterossexual, homossexual, bissexual, cisgênera ou transgênera, para o relator não significa que um ou outro comportamento esteja correto, pois "tudo que não estiver juridicamente proibido, ou obrigado, está juridicamente permitido" (BRASIL, 2011 p. 15).

Se paira um silêncio sobre as práticas e as vivências das sexualidades, Michel Bozon (2003) enfatiza a importância da sexualidade na esfera da conjugalidade, sendo que a sexualidade assume um "papel essencial”, para o autor "na constituição e, depois, na manutenção da relação conjugal" (BOZON, 2003, p. 133). É importante registrar que não somente a vivência das sexualidades, mas também temas como a família e os afetos tomam uma centralidade nos estudos das homossexualidades, lesbianidades e homoparentalidades.

\footnotetext{
8 O gênero e a sexualidade não teriam seu lugar na luz pública, mas sim na penumbra da intimidade.

9 Coloca-se uma alternativa entre a politização à americana e a não politização à francesa [...] "para nós, se diz então, as questões sexuais relevam dos costumes e não da política, das maneiras privadas e não do debate público, da civilidade e não da Cidade".
} 
E possível pensar o silêncio legislativo brasileiro em relação a sexualidade como uma forma de moralidade? "Questionar as relações afetivo-sexuais no âmbito das relações íntimas do espaço privado" (GROSSI, 1998, p. 2) é uma das importantes contribuições dos movimentos feministas e LGBT, que também buscam propor mudanças no contexto social, político e jurídico. Se existe um silenciamento em relação às questões sexuais no ordenamento jurídico brasileiro, é preciso que "os operadores jurídicos considerem a realidade das relações de gênero nos mais diversos âmbitos em que estas se apresentam ao Poder Judiciário e à prática jurídica” (RIOS, 2011, p. 177). Se não existem leis que tratem da conjugalidade entre pessoas do mesmo sexo, esse fator pode catalisar "a clandestinidade das relações homoafetivas, na aparente ignorância de sua existência; a ausência de acolhida normativa significa rejeição" (BRASIL, 2011, p. 1234), como afirmou o ministro Luiz Fux.

Sobre o conceito de homossexualidades e lesbianidades, o ministro relator, ao não definir a vivência da homossexualidade como uma "preferência" ou "orientação", traz o conceito a partir de Carl Gustav Jung, para oquem "é entendida não como anomalia patológica, mas como identidade psíquica e, portanto, como equilíbrio específico que o sujeito encontra no seu processo de individuação" (BRASIL, 2011, p. 15). Segundo o ministro Carlos Ayres Brito (BRASIL, 2011), está "embutida, nesse modo instintivo de ser, a "preferência” ou “orientação" de cada qual das pessoas naturais (BRASIL, 2011, p. 16), utilizando as expressões entre aspas. Já o ministro Marco Aurélio afirma que a homossexualidade "não se trata de mera escolha" (BRASIL, 2011, p. 12). Luiz Fux (BRASIL, 2011) afirma, citando as diversas manifestações dos amici curiae, que "a homossexualidade é um fato da vida", e conclui que é uma orientação e não uma opção sexual" e que, portanto, ao se tratar de minorias, é "uma característica da personalidade do indivíduo".

A questão da homofobia também foi enfrentada pelos ministros/as, mesmo que a decisão tivesse uma maior concentração na dimensão do afeto e da sexualidade. Para eles/as, o fato de não ter sido enfrentada a matéria da conjugalidade de pessoas do mesmo sexo na legislação brasileira é um dos fatores que pode gerar violências e discriminações, o se caracteriza como "homofobia”. Para Gilmar Mendes, "a falta de um 
modelo institucional incentiva o quadro de discriminação" (BRASIL, 2011). O conceito de homofobia é um neologismo que "agrupou dois radicais gregos, homo (semelhante) e fobia (medo) para definir sentimentos negativos em relação a homossexuais e às homossexualidades" (JUNQUEIRA, 2007, P. 3). Daniel Borrillo (2010) define homofobia como:

A hostilidade geral, psicológica e social contra aqueles e aquelas que, supostamente, sentem desejo ou têm práticas sexuais com indivíduos de seu próprio sexo. Forma específica de sexismo, a homofobia rejeita, igualmente, todos aqueles que não se conformam com o papel predeterminado para o seu sexo biológico. Construção ideológica consistente na promoção de uma forma de sexualidade (hétero) em detrimento de outra (homo), a homofobia organiza uma hierarquização das sexualidades e, dessa postura, extrai dela consequências políticas (BORRILLO, 2010, p. 34).

Ainda está em discussão a aprovação da lei contra a homofobia, legislação que tornará crime a discriminação de pessoas por "gênero, sexo, orientação sexual e identidade de gênero" (BRASIL, 2006), que recentemente também foi objeto de discussão no STF. Dessa forma, mais uma vez o STF se torna a vanguarda em concessão de direitos para a população LGBT diante de um contexto conservador e homofóbico no legislativo brasileiro, que se acentuou em 2019, com a eleição de Jair Messias Bolsonaro. É importante lembrar que em um contexto histórico homofóbico (ou não) se dê "maior ou menor visibilidade das relações entre pessoas do mesmo sexo", pois "um ambiente social de condenação à homossexualidade afeta a declaração de tal prática sexual” (HEILBORN, 2006, p. 363-364). O não reconhecimento da conjugalidade e a impossibilidade de acesso aos direitos proporciona experiências violentas pelos casais e por isso o papel do STF no acesso aos direitos humanos para a população LGBT é tão importante no contexto atual:

Os padrões descritos para casais heterossexuais e homossexuais são semelhantes, ocorre que em função da falta de aceitação da família e da sociedade em geral e da ausência/dificuldade na realização de rituais normativos, como o casamento e o divórcio, estes são mais difíceis para serem atendidos pelos homossexuais. Esta falta de aceitação da família está presente quando casais de pessoas do mesmo sexo vivenciam relações afetivo-conjugais. Esse tipo de não-aceitação ou repulsa pode ser incluído no conceito de homofobia, já referenciado (NICHNIG, 2013, p. 238). 
Percebo a homofobia como um fator impeditivo para a concessão de direitos para gays e lésbicas no Brasil. Segundo Leandro Oliveira, a recusa de direitos pode ser entendida como uma das muitas formas pelas quais se apresentam o 'preconceito' e a 'discriminação' contra homossexuais (OLIVEIRA, 2013). Marco Aurélio também interpreta a homofobia como grande responsável pelo alto índice de homicídios no país, para o qual “o Brasil ocupa o primeiro lugar, no ranking mundial, com mais de 100 homicídios por ano, cujas vítimas foram trucidadas apenas por serem homossexuais" (BRASIL, 2011, p. 3). A homofobia também impede a conjugalidade entre pessoas do mesmo sexo como sugere a ministra:

[...] não está aqui a discutir, nem de longe, a covardia dos atos, muitos dos quais violentos, contrários a toda forma de direito, que a manifestação dos preconceitos tem dado mostra contra os que fazem a opção pela convivência homossexual. Contra todas as formas de preconceito, contra quem quer que seja, há o direito constitucional. [...] Considerando o quadro social contemporâneo, no qual se tem como dado da realidade, uniões homoafetivas, a par do que se põe, no Brasil, reações graves de intolerância quanto a pessoas que, no exercício da liberdade que lhes é constitucionalmente assegurada, fazem tais escolhas, parece-me perfeitamente razoável que se interprete a norma em pauta em consonância com o que dispõe a Constituição em seus princípios magnos (BRASIL, 2011, p. 1254).

O reconhecimento das conjugalidades está envolto ao "desrespeito, materializado em condutas e declarações homofóbicas, aparece com frequência quando o assunto é união civil entre pessoas do mesmo sexo" (RIOS, 2011, p. 91). Para o autor por não temos uma lei que assegure esse direito a vivência da conjugalidade gay e lésbica se tornam “objeto de regulação alheia, meios para afirmação da superioridade da heterossexualidade e da abjeção da homossexualidade, ao invés de seres humanos cujas vidas merecem respeito e consideração" (2011, p. 91).

As únicas justificativas para ainda estarmos diante de um quadro de distinção entre as uniões entre homossexuais e heterossexuais são "o preconceito e a intolerância, enfaticamente rechaçados pela Constituição" (BRASIL, 2011, p. 1230), afirmou o ministro Luiz Fux que inda destacou o fato homossexualidade ser tratada "através da violência simbólica mas, o que é pior, da violência física perpassada por várias gerações" (BRASIL, 2011, p. 1248). 


\section{O processo judicial como locus da proteção dos direitos humanos e fundamentais: destaque para os Princípios Constitucionais}

Como afirmei, os princípios constitucionais foram utilizados como forma de buscar o reconhecimento de direitos de casais de pessoas do mesmo sexo e minha análise parte do voto dos/as ministros/as do STF, pois esse é o tribunal competente, no Brasil, para julgar as causas que envolvam descumprimentos dos preceitos constitucionais. Destaquei a ênfase dos princípios dada por cada um dos ministros sendo que:

[... [o voto dos ministros Luiz Fux e Carmem Lúcia, Joaquim Barbosa e Marco Aurélio trazem os princípios constitucionais para reconhecer o direito, dignidade da pessoa humana, não discriminação e igualdade. Gilmar Mendes, além dos princípios da dignidade da pessoa humana, não discriminação e igualdade, acrescenta o da liberdade. O Ministro Carlos Ayres Brito e Celso de Mello tratam dos princípios da dignidade da pessoa humana, não discriminação e igualdade, liberdade, autodeterminação, pluralismo, intimidade e da busca da felicidade. (NICHNIG, 2013, p.240)

A Constituição destaca, no artigo $1^{\circ}$, que seus fundamentos são a soberania, a cidadania, a dignidade da pessoa humana, os valores sociais do trabalho e da livre iniciativa e o pluralismo político, os quais são princípios fundamentais de direitos humanos, expressos no texto constitucional brasileiro. Se nos processos analisados se objetivou um alargamento do conceito de família, segundo Luiz Fux (2011) "não pode haver compreensão constitucionalmente adequada do conceito de família que aceite o amesquinhamento dos direitos fundamentais" (BRASIL, 2011, p. 1228). Na decisão há a utilização dos princípios constitucionais como instrumento para a garantia dos direitos fundamentais, em que "a interpretação constitucional de princípios, por ser indissociável de uma argumentação prática moral, conduz a uma reconstrução do texto constitucional" (NIGRO, 2012, p. 158)

O respeito à dignidade da pessoa humana, além de ser um fundamento da República Federativa do Brasil, é um dos princípios de nossa Constituição, em seu artigo terceiro, inciso quarto, e está presente no voto da maioria dos ministros, de forma expressa. Roger Raupp Rios enfatiza que o princípio da dignidade da pessoa humana tratado na decisão "é um direito humano básico" (2011, p. 90) e o fato de "não 
reconhecer o valor de uniões homossexuais, de importância ímpar para a existência e realização pessoal, com tão grave comprometimento do modo de viver e de existir do ser humano, é violação frontal à dignidade" (2011, p. 90).

O princípio da dignidade da pessoa humana está relacionado ao direito da personalidade, é bastante utilizado nos tribunais quando se defronta questões que tratam de família. Luiz Fux (2011) enfatiza a discussão ao afirmar que "rios de tinta já correram no Brasil e no exterior sobre o assunto", mas para o ministro é importante “rememorar que sua consagração no artigo primeiro inciso terceiro da Constituição Federal, traduz-se na previsão de que o indivíduo mereça do Estado e dos particulares, o tratamento de sujeito e não de objeto de direito, respeitando-se-lhe a autonomia, pela sua simples condição de ser humano" (BRASIL, 2011, p. 1232).

Nas questões que se relacionam ao direito de família, a igualdade civil é uma importante reivindicação que se faz presente no contexto brasileiro e está presente tanto no contexto da primeira onda feminista em que se reivindicava igualdade política e civil, como nos anos 1970, em que a pauta liberal por igualdade de direitos se faz presente. 0 princípio da igualdade é utilizado no caso em debate para demonstrar que a todos é possível unir-se em família, pois "sob o prisma da igualdade, o reconhecimento da sociedade homoafetiva é um consectário dos ditames constitucionais, é um respeito que se tem de ter pelas cláusulas pétreas constitucionais". E segue seu voto trazendo conceitos de igualdade propostos por Ronald Dworkin, que trata do contexto norteamericano, por Ernst Benda, Nancy Fraser, Hanna Arendt, citando ainda a tese de doutoramento de María Martin Sanchez (BRASIL, 2011, p. 1232). Luiz Fux (2011) interpreta o direito dos casais homossexuais a partir do que a norte-americana Nancy Fraser tratou de "política do reconhecimento", citando a obra publicada no Brasil que contém um texto da autora (BRASIL, 2011, p. 1233). Para o ministro, o reconhecimento implica em segurança, certeza e previsibilidade de que o direito será reconhecido caso interpelado. 0 princípio da igualdade entre homens e mulheres foi lembrado pelo Ministro Marco Aurélio Melo (BRASIL, 2011, p. 11). Da mesma forma, foi trazido pela Ministra Carmem Lúcia "porque se tem o direito de ser tratado igualmente no que diz respeito à própria 
humanidade e o direito de ser respeitado como diferente em tudo, a individualidade de cada um" (BRASIL, 2011, p. 1259).

No contexto francês, Régine Dhoquois chama a atenção para a importância do fato dos movimentos feministas estarem à frente das demandas por igualdade, destacando também, a atuação de advogadas e juristas francesas que fazem coro às reivindicações feministas por igualdade (DHOQUOIS, 2001). A historiadora Joan W. Scott (2001) que, ao afirmar que "a diferença sexual é o efeito de processos históricos e politicamente específicos que devem ser revertidos", o que auxilia a e pensar como alguns direitos são permitidos a uns e não a outros. A historiadora que discute o movimento por paridade no contexto francês propõe que a desigualdade deve ser corrigida através das leis, e que a suposta neutralidade da diferença sexual serviu para legitimar a exclusão das mulheres, primeiro da cidadania e depois da participação política, pois a luta por paridade abre um novo debate sobre o futuro da política francesa (SCOTT, 2001).

Assim "a existência de dois pesos e duas medidas, ao mesmo tempo com consequências protetoras e positivas para uns (heterossexuais) e prejudiciais e negativas para outros (homossexuais) é, sem dúvida, uma volição do direito de igualdade" (RIOS, 2011, p. 93). Assim, o propósito do princípio da igualdade é não enfrentar discriminações e "um contexto frontalmente oposto àquilo que o princípio da igualdade manda: não discriminar" (RIOS, 2011, p. 93).

É importante lembrar que a Constituição incluiu a discriminação com base no sexo, estando entre seus objetivos fundamentais a promoção do bem de todos, "sem preconceitos de origem, raça, sexo, cor, idade e quaisquer outras formas de discriminação" e, ainda, a inclusão do princípio da igualdade em "homens e mulheres são iguais em direitos e obrigações". Entretanto, não ficou expressa a proibição por discriminação com base na orientação sexual. Segundo Câmara (2002, p. 36), durante o período da Constituinte houve uma demanda de grupos homossexuais, como o Triângulo Rosa, para inclusão no texto constitucional, como na promoção de políticas públicas, leis e ações que pudessem ajudar a diminuir a discriminação contra os homossexuais. Ainda que o movimento homossexual incluísse a luta por direitos, a maior importância se deu 
durante a Constituinte de 1988. Assim, o fato de não estar expressão "orientação sexual” como um dos marcadores de discriminação foi chamado por Arriola como "preconceito antigay" pois segundo o autor este "não difere de nenhuma outra forma de discriminação tida como incompatível com a garantia constitucional de igualdade perante a lei" (ARRIOLA, 1994, p. 388). Ainda que não tenha previsão expressa na Constituição, a não discriminação por “orientação sexual”, na decisão do STF foi utilizada a proibição da não discriminação por "sexo", sendo a proteção dos direitos dos homossexuais pleiteada como uma da forma de proteção aos direitos humanos.

Ao utilizar o termo sexo, interpreto que o ministro Carlos Ayres Brito (2011) se referia à orientação sexual, ao se considerar que o exercício da sexualidade não pode servir para desigualação jurídica:

[...] o sexo das pessoas, salvo expressa disposição constitucional em contrário, não se presta como fator de desigualação jurídica. É como dizer: o que se tem no dispositivo constitucional aqui reproduzido em nota de rodapé (inciso IV do art. $3^{\circ}$ ) é a explícita vedação de tratamento discriminatório ou preconceituoso em razão do sexo dos seres humanos. Tratamento discriminatório ou desigualitário sem causa que, se intentado pelo comum das pessoas ou pelo próprio Estado, passa a colidir frontalmente com o objetivo constitucional de "promover o bem de todos (este o explícito objetivo que se lê no inciso em foco) (BRASIL 2011, p. 10).

Já o ministro Gilmar Mendes (2011) utiliza o princípio da "não discriminação por razão de opção sexual” (BRASIL, 2011, p. 1292), e segue tratando a homossexualidade como uma opção e não uma orientação dos indivíduos.

Para Marco Aurélio Mello (2011), a Constituição permitiu o reconhecimento da conjugalidade entre pessoas do mesmo sexo através das lentes do direito de família, sendo que a terminologia utilizada incluir a noção de afeto nas relações e por isso culminou com o uso do termo uniões homoafetivas, termo que tem sua origem no campo jurídico (NICHNIG, 2013). Assim, para o ministro, "relegar as uniões homoafetivas às disciplinas da sociedade de fato é não reconhecer essa modificação paradigmática no Direito Civil, levada a cabo pela Constituição Federal. A categoria da sociedade de fato reflete a realização de um empreendimento conjunto, mas de nota patrimonial, não 
afetiva ou emocional” (BRASIL, 2011, p. 1375). O ministro Cezar Peluso (2011) menciona que, há mais de vinte anos, foi autor da primeira decisão que entendeu não se aplicar às uniões estáveis as regras da sociedade de fato e sim enquadrá-las como entidade familiar, fazendo esta afirmação durante o seu voto no STF, segundo ele, "não por questão de vaidade, mas por registro histórico" (BRASIL, 2011, p. 1434).

O princípio da liberdade também se relaciona com o princípio da não discriminação e da igualdade, pois ambos têm efetividade quando o princípio da liberdade é respeitado. Nesse sentido, analiso tanto a liberdade como uma escolha da vivência da conjugalidade gay e lésbica como a liberdade sexual. A liberdade individual, "a escolha de uma união homoafetiva é individual, íntima e, nos termos da Constituição brasileira, manifestação da liberdade individual” (BRASIL, 2011, p. 2-3) pressupõe que a escolha da experiência da conjugalidade, seja hétero ou homossexual deve ser respeitada. A decisão final do processo considerou o respeito a liberdade como uma Cláusula Pétrea de nossa constituição que se traduz na "liberdade para dispor da própria sexualidade, inserida na categoria dos direitos fundamentais do indivíduo, expressão que é da autonomia da vontade. Direito à intimidade e à vida privada." O acórdão traz ainda a expressão “reconhecimento do direito à preferência sexual como direta emanação do princípio da "dignidade da pessoa humana", direito à autoestima no mais elevado ponto de consciência do indivíduo" (BRASIL, 2011).

Ao se falar em liberdade, deve se buscar o respeito ao "espaço de intimidade de cada um”, ou ainda "direito à liberdade de que cada ser humano é titular, para escolher o seu modo de vida, aí incluído a vida afetiva" (BRASIL, 2011, p. 1260). Segundo a Ministra Carmem Lúcia:

[...] também é objeto de expresso reconhecimento e resguardo constitucional (art. $5^{\circ}$, inc. X), que projeta para o plano social a eleição sentimental feita pelas pessoas e que merece não apenas a garantia do Estado do que pode ser escolhido, mas também a segurança estatal de que não sejam as pessoas alvo de destratamento ou discriminação pelo exercício desta sua liberdade (BRASIL, 2011, p. 1261).

Desta forma, o Estado deve assegurar o respeito a esta escolha individual, que seja respeitada a sua liberdade sexual, possibilitando o reconhecimento das variadas práticas 
sexuais. Assim, “os direitos de liberdade e de privacidade têm desdobramentos evidentes nos direitos sexuais, englobando não só o exercício das preferências sexuais, os estilos de vida e as identidades que se associam à vivência da sexualidade" (RIOS, 2011, p. 91). Carmem Lúcia afirma que a dignidade se relaciona com a liberdade pois “[...] para ser digno há que ser livre. E a liberdade perpassa a vida de uma pessoa em todos os seus aspectos, aí incluído o da liberdade de escolha sexual, sentimental e de convivência com outrem" (BRASIL, 2011, p. 6).

Ao ser assegurado o respeito ao princípio da liberdade sexual e o que ela chamou de "integridade humana de cada qual", temos que preservar a "liberdade de que cada ser humano é titular para escolher o seu modo de vida, aí incluído a vida afetiva com o outro" (BRASIL, 2011, p. 9). Nesse ponto, apesar de tratar da liberdade sexual ao se referir ao modo de vida, enfatiza a "vida afetiva" e não aponta a questão da vivência sexual, afirmando então que neste julgamento foi ressaltado o afeto presente nas convivências conjugais, e, portanto, o termo afetividade foi utilizado na decisão:

Na decisão do Supremo Tribunal Federal que reconheceu a união estável entre pessoas do mesmo sexo como entidade familiar, o temo homoafetividade foi utilizado na decisão "para identificar o vínculo de afeto e solidariedade entre os pares ou parceiros do mesmo sexo, que não constava dos dicionários da língua portuguesa” (BRASIL, 2011, p. 7). De acordo com o ministro Carlos Ayres Brito este termo "foi cunhado pela vez primeira na obra "União Homossexual, o Preconceito e a Justiça", da autoria da desembargadora aposentada e jurista Maria Berenice Dias" (BRASIL, 2011, p. 8). Cita ainda o conceito de homoafetividade criado pela própria advogada, que demonstra que as terminologias homossexualismo e homossexualidade ainda são carregadas de estigmas e preconceitos, portanto foi necessário que uma nova terminologia jurídica fosse apresentada pela jurista, a qual é citada no voto do ministro (NICHNIG, 2013, p. 171-172).

E desse modo que asseguro que quando trato de direitos de igualdade não só enfoco questões liberais, como o respeito a igualdade e as liberdades individuais, mas sobretudo que estas práticas sexuais também se traduzem em importantes lutas identitárias dos sujeitos.

Relacionando os princípios da dignidade da pessoa humana e da liberdade sexual, alguns ministros e ministras relacionam com a ideia de que este respeito proporciona a 
"busca da felicidade". Assim, se os casais de pessoas do mesmo sexo têm assegurada a liberdade para vivenciar sua conjugalidade de forma a que não sofram violências e preconceitos e possam buscar a felicidade e uma vida digna, o que foi expresso na parte principal do acórdão, a ementa: “Direito à busca da felicidade. Salto normativo da proibição do preconceito para a proclamação do direito à liberdade sexual”.

Vale lembrar que a busca da felicidade foi um dos princípios assegurados na declaração de independência norte-americana, analisados por Lynn Hunt (2009) como fundante dos direitos humanos (HUNT, 2009). O historiador Leandro Karnal (2006) mostra como a Guerra da Independência dos Estados Unidos da América, como um momento histórico que traz uma nova concepção política que permite trazer os conceitos de cidadania e liberdade à discussão. A declaração de independência americana afirmava que "[...] todos os homens foram criados iguais e dotados pelo Criador de direitos inalienáveis, como a vida, liberdade, busca da felicidade" (KARNAL, 2006, p. 142). Para o ministro Celso de Mello (2011), a busca da felicidade pode ser um princípio derivado do princípio da dignidade da pessoa humana, e ao referenciar autores estadunidenses, como Ray Raphael e Stephanie Schwartz Driver, concede esse caráter universalizante pois o “direito à busca da felicidade como prerrogativa fundamental inerente a todas as pessoas" (BRASIL, 2011, p. 1417). Luiz Fux (2011) apresenta conjugalidade gay e lésbica como sendo "mais do que um projeto de vida, um projeto de felicidade" (BRASIL, 2011, p. 1271). O relator do processo enfatizou o direito das pessoas homossexuais de serem felizes, pois "se as pessoas de preferência heterossexual só podem se realizar ou serem felizes heterossexualmente, as de preferência homossexual seguem na mesma toada: só podem se realizar ou ser felizes homossexualmente. Ou homoafetivamente, como hoje em dia mais e mais se fala [...] (BRASIL, 2011, p. 20-21).

A dimensão do afeto e do amor "deixou de ser um meio de acesso à felicidade para tornar-se seu atributo essencial” (FREIRE COSTA, 1998, p. 19), o que nos faz perceber a centralidade das questões subjetivas, a ênfase nos sentimentos e nos afetos das relações. Mabel Moraña mostra como "los distintos autores asignan diferentes valores y características, por ejemplo, a emociones, sentimientos, pasiones y deseos, según su duración, foco, intensidad, modalidades de proyección interindividual” 
(MORÃNA, 2012, p. 317) ${ }^{10}$. Dessa forma, os estudos de gênero, as teorias feministas e as teorias queer impulsionaram um "giro afetivo" que "permitiría iluminar bajo una nueva luz aspectos de la relación entre lo social y lo subjetivo que de otro modo escaparían a nostra percepción" (MORAÑA, 2012, p. 317). ${ }^{11}$

Ao enfatizar a busca da felicidade como um princípio, mesmo que não previsto na constituição, é possível refletir sobre a centralidade das emoções e dos sentimentos na constituição dos sujeitos e das práticas políticas. Os sentimentos, as emoções são acionados e constituem "parte do discurso e da ação política" (WOLFF, 2015, p. 977), e são acionados também na ação política que busca por direitos. Os usos do gênero que nos ensina Cristina Scheibe Wolff também mobilizam as pessoas em torno de uma prática política, neste caso muito utilizada quando se referia ao respeito aos direitos humanos dos perseguidos e presos políticos no período da ditadura militar, estudado pela historiadora (WOLFF, 2015).

Moraña (2012), ao tratar do estudo das emoções enfatiza que este é "una de las líneas de fuga de la modernidad: la energía nomádica que circula en el ámbito de lo social resistiendo el control disciplinario del estado y sus instituciones" (MORAÑA, 2012, p. 315)..$^{12}$ Amar é revolucionário e ao reivindicarem direitos, as famílias gays e lésbicas no Brasil propõem um ato político de resistência. Sim! Existimos!

\section{Considerações finais}

A centralidade dos princípios constitucionais na decisão que assegurou o reconhecimento das conjugalidades de gays e lésbicas como família me permite concluir que este é uma forma dar efetividade dos direitos humanos no Brasil. Mesmo que aquela decisão tenha sido um grande passo no reconhecimento de direitos da população LGBT, uma grande conquista, como declarou o ministro Carlos Ayres Brito na palestra magna

\footnotetext{
${ }^{10}$ Os diferentes autores assinalam diferentes valores e características, por exemplo, emoções, sentimentos, paixões e desejos, segundo sua duração, foco, intensidade, modalidades de projeção interindividual.

${ }^{11}$ Permitiria iluminar sob uma nova luz aspectos da relação entre o social e o subjetivo que de outro modo escaparia à nossa percepção. (tradução minha)

${ }^{12}$ Uma das linhas de fuga da modernidade: a energia nômade que circula no âmbito do social resistindo ao controle disciplinar do Estado e suas instituições.
} 
que abriu a Segunda Conferência Nacional de Políticas Pública LGBT, em dezembro de 2011, alguns temas não puderam ser abordados. O ministro fazia referência ao direito ao casamento e à adoção por casais do mesmo sexo.

A decisão considerada histórica ${ }^{13}$, de maio de 2011, foi a porta de entrada para outras decisões favoráveis a causa LGBT, como o reconhecimento ao direito ao casamento entre pessoas do mesmo sexo, através da decisão do Conselho Nacional de Justiça, de 14 de maio de 2013, que proíbe a recusa de habilitação, celebração de casamento civil ou de conversão de união estável em casamento entre pessoas de mesmo sexo (CNJ, 2013). Em ambos os casos foram os princípios constitucionais que são a positivação dos Direitos Humanos no Brasil que garantiram os direitos em detrimento da vivência da conjugalidade para as pessoas LGBT. A decisão colocou o Brasil no mesmo patamar de alguns países que já reconheciam direitos aos casais de pessoas do mesmo sexo, tanto como em situações semelhantes à união estável como o direito ao casamento, sendo que a decisão histórica de 2011 repercutiu de forma favorável em outros países.

Mesmo após a decisão de 2011, sigamos no desejo de uma existência de legislação específica em relação ao casamento e união estável, para que direitos de pessoas LGBT não sejam retirados, pois a existência de lei, mesmo que não cumprida ou deficiente, atua de forma a legitimar certos comportamentos ou a declará-los inadequados. No caso da igualdade de gênero, apesar da existência de uma legislação constitucional fundamentada na DUDH, que determinava formalmente esta igualdade, nem sempre essa igualdade é respeitada. Vem daí, pois, a necessidade de atuação dos movimentos sociais, como os feministas e LGBT, como meio de pressão para o cumprimento da legislação. Desta forma, para que a lei se transformasse em instrumento de mudança social, era necessário que estas transformações legislativas estivessem acompanhadas de

\footnotetext{
13 Apesar de não constar da página dos chamados “julgamentos históricos” pelo Tribunal, o processo aqui analisado foi grafado com a expressão "possui tema relevante conforme Res. 474/11", ou seja, na própria consulta ao processo, no site do Supremo Tribunal é possível observar esta informação. Por ser considerado como "tema relevante" o processo portador de "potencial histórico" recebe do Supremo Tribunal Federal um selo "Tema Relevante” afixado na capa. Ver: Artigo 8, parágrafo único da Resolução 474/2011. Disponível em: <http://www.stf.jus.br/ARQUIVO/NORMA/RESOLUCAO474-2011.PDF>. Acesso em: 15 fev. 2013 .
} 
"um forte e continuado apoio dos movimentos sociais" (TABAK e VERUCCI, 1994, p. 44). O ministro Marco Aurélio afirmou que "as modificações pelas quais a família passou não impediram a permanência de resquícios de modelos antigos" (BRASIL, 2011, p. 1372), ou seja, estamos certos que a família é uma construção dada em certos contextos históricos e permeadas por uma cultura.

A posição vanguarda no reconhecimento de direitos para a população LGBT pelo STF novamente pode ser observada na decisão proferida em 2019, que reconheceu a homofobia como crime, "entendeu que houve omissão inconstitucional do Congresso Nacional por não editar lei que criminalize atos de homofobia e de transfobia" e por esse motivo "a Corte reconheceu a mora do Congresso Nacional para incriminar atos atentatórios a direitos fundamentais dos integrantes da comunidade LGBT" (STF, 2019). A decisão proferida em um momento tão turbulento de nossa história para a discussão das questões de gênero e sexualidade não passaram em branco. O próprio presidente afirmou "A decisão do Supremo, com todo respeito que eu tenho aos ministros, é completamente equivocada. Além de estar legislando, está aprofundando a luta de classes", e ainda afirma que "decisão do STF sobre homofobia foi 'completamente equivocada'" (G1, 2019). Ora o próprio presidente entende que heterossexuais e homossexuais são de "classes" diferentes? Que "luta de classes" ele se refere? Não somos nós todos/as/es detentores de direitos humanos? Assim, diante de possíveis e já visíveis retrocessos, o caminho para uma positivação dos Direitos Humanos no Brasil, principalmente quando se trata de direitos das minorias, segue como uma questão urgente. 


\section{Referências}

ALMEIDA, Miguel V. de. A chave do armário: Homossexualidade, Casamento e família. Florianópolis: UFS, 2010.

AMORIM, Anna C. H. Nós já somos uma família, só faltam os filhos: maternidade lésbica e novas tecnologias reprodutivas no Brasil. Dissertação (Mestrado). Programa de PósGraduação em Antropologia Social. Universidade Federal de Santa Catarina. Florianópolis, 2013.

AREND, Silvia M. F.; MACEDO, F. Sobre a história do tempo presente: entrevista com o historiador Henry Rosso. Tempo e Argumento. Florianópolis, v. 1, n. 1, p. 201-216, jan./jun. 2009.

ARRIOLA, Elvia R. Desigualdade de gênero: lésbicas, gays e teoria legal feminista. Estudos Feministas. Florianópolis, v.2, n.2, p. 388-427, 1994.

BORRILLO, Daniel. Homofobia: história e crítica de um preconceito. Belo Horizonte: Autêntica, 2010.

BOZON, Michel. Sexualidade e conjugalidade: A redefinição das relações de gênero na França. Cadernos Pagu. Campinas, v.20, p. 131-156, 2003.

BRASIL. Lei Lei 10.406, de 10 de janeiro de 2002. Disponível em: «www.planalto.gov.br» Acesso em 17 jun. 2019.

BRASIL. Lei 12.010, de 03 de agosto de 2009. Disponível em: «www.planalto.gov.br» Acesso em: 28 maio 2019 .

BRASIL. Projeto de lei n. 5003/2001 (PLC 122/2006). Disponível em «www.planalto.gov.br»

BRASIL. Supremo Tribunal Federal. Ação Direta de Inconstitucionalidade n. 4177. Brasília, STF, 2011.

BUNCHAFT, Maria E. Constitucionalismo democrático versus minimalismo judicial. Direito, Estado e Sociedade. Rio de Janeiro, n.38, p. 154-180, jan.-jun. 2011.

BUTLER, Judith R. Problemas de gênero: feminismo e subversão da identidade. Rio de Janeiro: Civilização Brasileira, 2003.

CÂMARA, Cristina. Cidadania e orientação sexual: a trajetória do Grupo Triângulo Rosa. Rio de Janeiro: Academia Avançada, 2002. 
CONSELHO Nacional de Justiça. Disponível em: «http://www.cnj.org.br» Acesso em: 14 maio 2013.

COSTA, Jurandir F. Sem fraude nem favor. Rio de Janeiro: Rocco, 1998.

COURDURIÈS, Jérôme; FINE, Agnès (orgs.). Homosexualité et parenté. Paris: Armand Colin, 2014.

DHOQUOIS, Régine. La recherche féministe à l'université dans le domaine du droit. Une absence en forme de désertion. Les Cahiers du CEDREF. Paris, n.10, 2001. Disponível em: «http://cedref.revues.org/278». Acesso em: 5 jun. 2010.

Dosse, François. História do tempo presente e historiografia. Tempo e Argumento. Florianópolis, n.4, 2012, 4. Disponível em:

«http://www.redalyc.org/articulo.oa?id=338130378002» Acesso en : 12 jun. 2019.

FABRE, Clarisse; FASSIN, Éric. Liberté, égalité, sexualités: actualité politiques des questions sexuelles. Paris: Belfond, 2003.

FONSECA, Cláudia. Homoparentalidade: novas luzes sobre o parentesco. Estudos Feministas. Florianópolis, v.16, n.3, p. 769-783, 2008.

FOUCAULT, Michel. A arqueologia do saber. Rio de Janeiro: Forense Universitária, 2009.

FRASER, Nancy. Redistribuição, reconhecimento e participação, por uma concepção integrada de justiça. In: SARMENTO, Daniel; IKAWA, Daniela; PIOVESAN, Flávia. Igualdade, diferença e direitos humanos. Rio de Janeiro: Lumen Juris, 2010.

GROSSI, Miriam P. Identidade de gênero e sexualidade. Antropologia em Primeira Mão. Florianópolis, n. 24, 1998. p. 1-15. (versão atualizada 2010).

GROSSI, Miriam P. Gênero e parentesco: famílias gays e lésbicas no Brasil. Cadernos Pagu. Campinas, n. 21, p. 261-280, 2003.

GROSSI, Miriam P. UZIEL, Anna P.; MELLO, L. (orgs.) Conjugalidades, parentalidades e identidades lésbicas, gays e travestis. Rio de Janeiro: Garamond, 2007.

G1. Bolsonaro diz que decisão do STF sobre homofobia foi completamente equivocada. Disponível em: «https://g1.globo.com/jornal-nacional/noticia/2019/06/14/bolsonaro-dizque-decisao-do-stf-sobre-homofobia-foi-completamente-equivocada.ghtml» Acesso em 18 jun. 2019. 
HALL. Stuart. Quem precisa de identidade. In: SILVA, Tomaz T. da (org.) Identidade e diferença: a perspectiva dos estudos culturais. Petrópolis: Vozes, 2000.

HEILBORN, Maria L. Construção de si, gênero e sexualidade. In: . (org.) Sexualidade: o olhar das Ciências Sociais. Rio de Janeiro: Zahar, 1999. p. 40-58.

HEILBORN, Maria L. et al. (org.) O aprendizado da sexualidade: reprodução e trajetórias sociais de jovens brasileiros. Rio de Janeiro: Garamond, 2006.

HUNT, Lynn. A invenção dos direitos humanos: uma história. São Paulo: Companhia das Letras, 2009.

JUNQUEIRA, Rogério D. Homofobia: limites e possibilidades de um conceito em meio a disputas. Bagoas, Natal, n.1, v. 1, p. 145-166, jul.-dez. 2007.

KARNAL, L. Estados Unidos, liberdade e cidadania. In: PINSKY, Jaime; PINSKY, Carla B. (orgs.) História da cidadania. 4.ed. São Paulo: Contexto, 2006.

MACIEL, Débora A.; KOERNER, Andrei. O sentido da judicialização da política: duas análises. Lua Nova. São Paulo, n.57, p.113-134, 2002.

MELLO, Luiz. Novas famílias: conjugalidade homossexual no Brasil contemporâneo. Rio de Janeiro: Garamond, 2005

MORAÑA, Mabel. Postscríptum. El afecto em la caja de herramientas. In: MORAÑA, Mabel; PRADO, Ignácio M. S. (orgs.) El lenguaje de las emociones: afecto y cultura en América Latina. Madrid/Frankfurt: Iberoamericana, 2012.

NICHNIG, Claudia R. Para ser digno há de ser livre: reconhecimento jurídico da conjugalidade entre pessoas do mesmo sexo no Brasil. Tese (Doutorado em Ciências Humanas). Programa de Pós-Graduação Interdisciplinar em Ciências Humanas, Universidade Federal de Santa Catarina. Florianópolis, 2013.

NICHNIG, Claudia R. O reconhecimento jurídico da conjugalidade entre pessoas do mesmo sexo: participação da sociedade civil durante o julgamento do STF de maio de 2011. In: GROSSI, Miriam P.; FERNANDES; Felipe B. M. A força da situação em campo: ensaios sobre antropologia e teoria queer. Florianópolis: Editora da UFSC, 2018. p. 305324.

NICHNIG, Claudia R. Os Estudos de Gênero revolucionaram a História? Algumas provocações a partir do Ensino de História. InterMeio: Revista do Programa de PósGraduação em Educação. Campo Grande, 2019. No prelo. 
NIGRO, Rachel. Decisão do STF sobre a união homoafetiva: uma versão pragmática da linguagem constitucional. Direito, Estado e Sociedade. São Paulo, n.41, p. 157-183, jul.-dez. 2012.

OLIVEIRA, Leandro de. Os sentidos da aceitação: Família e orientação sexual no Brasil contemporâneo. Tese (Doutorado). Programa de Pós-Graduação em Antropologia Social. Universidade Federal do Rio de Janeiro, Museu Nacional. Rio de Janeiro, 2013.

RIBEIRO, Gustavo L. Cidadania e minorias no mundo globalizado. In: LIMA, Antonio C. de S. (org.) Antropologia \& Direito: temas antropológicos para estudos jurídicos. Rio de Janeiro/Brasília: Contra Capa/LACED/Associação Brasileira de Antropologia, 2012. p. 219225.

RIOS, Roger R.; GOLIN, Célio; LEIVA, Paulo G. C. Homossexualidade e direitos sexuais: reflexões a partir da decisão do STF. Porto Alegre: Sulina, 2011.

ROUDINESCO, Elisabeth. A família em desordem. Rio de Janeiro: Zahar, 2003.

SCOTT, Joan W. La querelle des femmes no final do século XX. Estudos Feministas. Florianópolis, v. 9, n. 2, p. 367-388, 2001.

SCHRITZMEYER, Ana L. P. Jogo, ritual e teatro: um estudo antropológico do Tribunal do Júri. São Paulo: Terceiro Nome, 2012.

SUPREMO Tribunal Federal. Disponível em: Disponível em: «http://www.stf.jus.br/portal/cms/verNoticiaDetalhe.asp?idConteudo=414010» Acesso em: 18 jun. 2019.

TABAK, Fanny; VERUCCI, Florisa. A difícil igualdade: os direitos da mulher como direitos humanos. Rio de Janeiro: Relume-Dumará, 1994.

TARNOVSKI, Flávio L. Pais assumidos: adoção e paternidade homossexual no Brasil contemporâneo. Dissertação (Mestrado). Programa de Pós-Graduação em Antropologia Social. Universidade Federal de Santa Catarina. Florianópolis, 2002.

UNICEF. Disponível em: «https://www.unicef.org/brazil/pt/resources_10133.html» Acesso em: 1 fev. 2019.

UNRIC. 2018 comemora os 70 anos da Declaração Universal dos Direitos Humanos, Bruxelas: ONU, 6 dez. 2017. Disponível em: «https://www.unric.org/pt/actualidade/323692018-comemora-os-70-anos-da-declaracao-universal-dos-direitos-humanos» Acesso em: 1 dez. 2018. 
VIANNA, Luiz W. A judicialização da política no Brasil. In: VIANNA, Luiz W. A judicialização da política e das relações sociais no Brasil. Rio de Janeiro: Editora Revan, 1999. p. 47-70.

VIANNA, Luiz W.; BURGOS, Marcelo B.; SALLES, Paula M. Dezessete anos de judicialização da política. Tempo Social. São Paulo, v. 19, n. 2, p. 39-85, 2007.

WITTIG, Monique. La pensée straight. Paris: Amsterdam, 2007.

WOLFF, Cristina S. Pedaços de alma: emoções e gênero no discurso das resistências.

Estudos Feministas. Florianópolis, v. 23, n. 3, p. 975-989, set.-dez. 2015.

ZAMBRANO, Elizabeth; HEILBORN, Maria L. Identidade de gênero. Antropologia \& Direito: temas antropológicos para estudos jurídicos. Rio de Janeiro/Brasília: Contra Capa/LACED/Associação Brasileira de Antropologia, 2012. p. 412-419.

Recebido em 11/01/2019 Aprovado em 28/05/2019

Universidade do Estado de Santa Catarina - UDESC Programa de Pós-Graduação em História - PPGH

Revista Tempo e Argumento Volume 11 - Número 27 - Ano 2019 tempoeargumento@gmail.com 